\title{
Constructing a Composite Leading Indicator for the Global Crude Oil Price
}

\author{
Mei-Teing Chong ${ }^{1}$, Chin-Hong Puah $^{1}$, Shazali Abu Mansor ${ }^{1}$ \\ ${ }^{1}$ Faculty of Economics and Business, Universiti Malaysia Sarawak, 94300 Kota Samarahan, Sarawak, Malaysia \\ Correspondence: Chin-Hong Puah, Faculty of Economics and Business, Universiti Malaysia Sarawak, 94300 \\ Kota Samarahan, Sarawak, Malaysia.
}

Received: March 9, 2018

doi:10.5539/ibr.v11n5p129

\author{
Accepted: April 17, $2018 \quad$ Online Published: April 23, 2018 \\ URL: https://doi.org/10.5539/ibr.v11n5p129
}

\begin{abstract}
Crude oil, as the most traded commodity in the world, exhibits prices with a clear influence on other commodities in the worldwide market. It also poses implications regarding the economic growth of oil-exporting and oil-importing nations. This study provides an unprecedented method of employing the indicator approach as proposed by the Conference Board, National Bureau of Economic Research, to construct a leading indicator for the global crude oil price. The results reveal that the constructed oil price indicator can predict the cyclical movement of the oil price by moving in advance of 3.5 months on average. This finding could provide better signaling to oil-related nations as well as other commodities that consider crude oil to be a leader in the market.
\end{abstract}

Keywords: crude oil price, forecasting, indicator approach

\section{Introduction}

Six years after the previous slump of crude oil prices (COPs) in 2008, the mid-2014 crude oil glut has written another page in the oil price shocks history. Unlike the depressive 2008 global financial crisis that caused many stocks to take a nosedive, oil market players claim the ongoing-markdown since mid-2014 is caused by the lead players in the field who are actually pulling the strings. After the COPs per barrel peaked in June 2014, where West Texas Intermediate (WTI) recorded at US \$105.79 and Europe Brent (Brent) tracked at US \$111.80, the overall COPs outlook will apparently remain bearish or less sanguine to bounce back in the short term. The November 2014 report by the International Energy Agency (IEA) offers no hope for an oil price recovery any time soon, suggesting that the bearish market might extend throughout the year 2016. Wall Street oil experts even believe that the already tense COPs will be exacerbated before rebalancing occurs in late 2016. Translating belief into fact, in January 2016, the WTI and Brent per barrel then dropped to US \$31.68 and US \$30.70, respectively. Many oil industry players worry that the oil price is dropping into a bottomless pit, and the worst is yet to come.

In the face of the sudden oil price collapse along with the volatility of the global crude oil market and country's dependency on oil exportations and energy-related industries, many have voiced their infinite concerns regarding the sustainability of the falling oil prices as well as how their government can tackle the underpinning forces of oil market fluctuations. Likewise, renewed interest in the oil market forecasting is resurging, as many are eagerly seeking insight into the future direction of the COPs. Almost all forecasting analyses on COPs and the oil futures market rely on complex computational modelling that requires heavy assumptions, modelling bias, and high cost of computational analysis. Complex computational modelling is not as cost-efficient and policy effective as the modelling bias, and a great deal of assumptions undermine the forecast accuracy. Therefore, it casts doubt on the ability of the globe to provide a timely response to any impending shocks in the absence of a well-defined and responsive forecasting mechanism.

During this century, when industrialized and developing nations lead world commerce, crude oil plays a vital role in the world economy as the backbone of all energy-related industries and downstream activities that make abundant use of the energy supply. In fact, crude oil is one of the exceedingly traded commodities in the worldwide marketplace and the most actively traded commodity in the future markets, consequently enabling it to be a focal source of income for major oil-exporting nations. Thus, market evolution and future scenarios of the crude oil market in the globe remain an indispensable learning to the policymakers and oil market players. 


\section{Literature Review}

Much of the previous studies have focused on characterizing the oil market through a demand and supply framework, estimating the correlation of oil price with others as well as its impacts, such as provided by Cong et al. (2008), Park and Ratti (2008), Aloui and Jammazi (2009), Soytas et al. (2009), and Wong and Shamsudin (2017). Furthermore, Haas et al. (2004), Agnolucci (2009), Cheong (2009) and Jo (2012) devoted effort to analyzing the volatility of the oil prices. Several studies forecasted the oil prices from standard econometric techniques and intelligent computing models such as artificial neural networks and fuzzy expert systems (see for example, Abramson and Finizza, 1991; Pan et al., 2009; and Azadeh et al., 2012).

Nevertheless, none of the previous studies devoted in the international crude oil market ever discussed the application of the indicator as a tool of short-term prediction for the COPs fluctuations. Almost all of the forecasting analyses on COPs and the oil futures market rely on complex computational modelling that requires heavy assumptions and modelling bias in addition to the cost of computational analysis. An indicator approach has been widely used in cyclical study. For example, Abu Mansor et al. (2015) and Wong et al. (2016) explored the indicator-based forecasting tool for business cycle analysis and economic risk monitoring, Puah et al. (2016a) tackled the macroeconomic precariousness by establishing a composite leading indicator for the Cambodian economy, and Puah et al. (2016b) applied these data within the property cycle study for Malaysia. Conversely, the indicator study, which is evidently cost-efficient and effective for cyclical analysis as well as future prediction, especially for the oil price market movement, has been neglected as a topic of study.

The present study seeks to fill the gap by constructing and cultivating an indicator-based forecasting tool which has been tested to foresee most of the cyclical processes of economic activities. In particular, the key goal of this study is to construct a composite leading oil price indicator (OPI) that offers a remarkable ability to predict the oil price dynamics in a forward-looking manner. The newly constructed OPI is projected to postulate well the cyclical movement of the international and domestic oil market, leading to the computation of oil market turning points and the strength of early signals. The application of such an indicator has been particularly successful in business cycle analysis, property market study, and credit cycle analysis. In short, the ideology of indicator construction is a theoretically and empirically appealing method to analyze and forecast the movement of the oil market. Thus, the application of indicator construction into the oil market will be an important endeavor to provide an understanding of the cyclical processes of the oil market from a global perspective. The resulting indicator is likely to contribute a better realization of the underlying information content behind the fluctuating oil market in the global market.

The OPI is expected to be a well-defined oil market signaling mechanism that assists the policymakers, oil market players, and the general public to cultivate timely precautionary measures so as to counteract the erratic oil market. Therefore, the application of OPI into future decision-making and policy establishment would lead to better policy actions, market stabilization, and oil-related development in the oil-exporting nations. Lastly, the OPI will be of great interest to the oil-producing companies in the design of business planning and contracts for oil- and gas-related exploration, and it will help all interested parties deal confidently in future crude oil markets. Despite all uncertainties, this study reckons that well-informed policymakers and business players will no doubt benefit in terms of effectiveness and efficiency in the face of any impending danger from the internal and external environments.

\section{Econometric Techniques}

Many believe that the evolution of the COPs follows a cyclical pattern. The drifting COP is a latent variable that postulates a broad sense of the market evolvement. However, the contemporary oil market does not merely rest with the conventional supply and demand, but also the external shocks (geopolitical risk and market expectations). Thus, the ideology of indicator construction first proposed by U.S. National Bureau of Economic Research (NBER) provides a profound framework to summarize the cyclical information from various perspectives of the oil market. To trace and predict the movement of the oil market, this study applies the well-known indicator construction method outlined by Moore and Zarnowitz (1986) to create a composite leading indicator of oil price dynamic-OPI, to gauge the cyclical development of the oil market from a global perspective, covering the period from January 2000 to June 2016.

As most of the indicator-based study, the first stage of OPI construction necessitates the selection of an oil market benchmark that reveals the development of the oil market in its current state. This benchmark will serve as a reference series to characterize the existing oil market. Thus, it will be responsible for the establishment of reference chronology for the oil market throughout the investigated period. In this case, it will be investigated for its validity and adequacy to serve as a well-defined oil market reference series. Consequently, turning point 
detection to recognize the peaks and troughs of the reference cycle will be performed. In order to identify the cyclical turning points of the oil market from a growth perspective, the reference series will be subjected to a set of transformation procedures that translate the reference series in its level form into a seasonally adjusted, detrended, and smoothed cyclical component before it is applied to the Bry-Boschan (1971) technique to establish the reference chronology for the global oil market.

Specifically, the transformation and cycle extraction procedures suggested by Moore and Zarnowitz (1986) will serve as an important reference manual at this stage. For seasonal adjustment, the Census X-12 method will be jointly tested for its suitability in this context before the most desirable one is chosen. On the other hand, the Christiano-Fitzgerald (CF) filter developed by Christiano and Fitzgerald (2003) will be applied to produce an alternative reference cycle based on the band-pass filtering approach. Accordingly, the best alternative will then be chosen as the ultimate reference cycle for reference chronology establishment.

It is widely known that there are several benchmarks of COPs being used worldwide, i.e. Brent, West Texas Intermediate (WTI) Cushing, and Dubai/Oman. The U.S. Energy Information Administration (EIA, 2014) states that Brent and WTI are the two chief crude oil benchmarks in the world, followed by the Dubai/Oman. Thus, this study will perform the process of both Brent and WTI as described previously to find out their cyclical development. In the subsequent stage, the OPI will be constructed by cautiously adopting the composite indicator construction and index compilation procedures documented in the Conference Board (2000). The OPI construction involves the selection of a set of component series, followed by the aggregation of the component series in its composite form and rebasing the composite index in a selected base year. The index aggregation procedure can be detailed as follows:

(i) Compute the month-to-month changes $\left(\mathrm{m}_{\mathrm{p}, \mathrm{t}}\right)$, where $\mathrm{p}=1, \ldots, \mathrm{n}$ for each component series $\left(\mathrm{x}_{\mathrm{p}, \mathrm{t}}\right)$ based on the symmetric percentage change formula below:

$$
m_{p, t}=\frac{X_{p, t}-X_{p, t-1}}{X_{p, t}+X_{p, t-1}} * 200
$$

Variable(s) in percentage form within the component series will be differenced on simple arithmetic (i.e. OPEC and non-OPEC crude oil production change, world crude oil consumption change and world crude oil stock change).

(ii) Measure the monthly input for each component series $\left(\mathrm{c}_{\mathrm{p}, \mathrm{t}}\right)$ by multiplying the month-to-month changes $\left(\mathrm{m}_{\mathrm{p}, \mathrm{t}}\right)$ with a standardization factor $\left(\mathrm{f}_{\mathrm{p}}\right)$. The standardization factor can be derived by inversing the standard deviation of the month-to-month changes for each component series $\left(\mathrm{m}_{\mathrm{p}, \mathrm{t}}\right)$.

(iii) Total up the adjusted symmetric changes across the component series to obtain the total contribution across all component series for a particular month,

$$
S_{t}=\sum_{p=1}^{n} c_{p, t}
$$

(iv) Set the first value of the index to 100 and derive the preliminary index of OPI recursively with the formula, as follows:

$$
I_{2}=\frac{200+S_{2}}{200-S_{2}} * I_{1}
$$

(v) Rebase the preliminary index of OPI into the base year of 2010.

After the construction of the OPI, the raw index then transforms into a growth cycle using the similar approach that applied to extract the cyclical component of the reference cycle. Graphical analysis will be performed to evaluate the movement of the cyclical component of OPI relative to the cyclical component of the reference cycle. To determine the turning points of OPI, the Bry-Boschan (1971) dating algorithm will be applied for the local minimum and local maximum values of the OPI in its cyclical form. Subsequently, comparative analysis of the dated turning points between OPI and the oil market reference cycle will be conducted to determine the effectiveness of the constructed OPI in predicting the movements of the oil market. 
There are many potential factors affecting the COPs, and yet it is practically impossible to include all of them in the construction of OPI. Strict criteria have been imposed in the selection of component series, among others, economic significance, cyclical behavior, similar time frame and frequency, and data availability. After all, the OPI in this study in particular, is constructed through seven component series, namely world crude oil production, world crude oil consumption, world crude oil inventory changes, WTI futures price, business confidence index of U.S., the central bank policy rate, and open interest. All of the variables are sourced from the U.S. EIA, except for business confidence index from the Organization for Economic Co-operation and Development (OECD) and the central bank policy rate from International Monetary Fund.

\section{Findings and Discussions}

Figure 1 shows the cyclical process of both OPI and WTI. This graphical comparative analysis depicts the predictive power of OPI in tracing the progression of WTI, as the former moves in advance of the cyclical movement of the latter. It then reveals that the constructed OPI is a desirable and visionary attribute in tracing the progress of WTI. Meanwhile, the OPI also divulges the correct signaling of the ups and downs of the WTI cycle by moving in advance of 3.5 months on average. It is wise to visualize that the OPI actually moves ahead of the WTI most of the time, as indicated by the shaded areas in Figure 1. Each shaded area represents different important events that affected oil prices over different time span and it is shaded from a peak to a trough in a cycle. Observing the examined time frame, OPI has dated 10 engrossing turning points including five peaks and five troughs, as tabulated in Table 1.

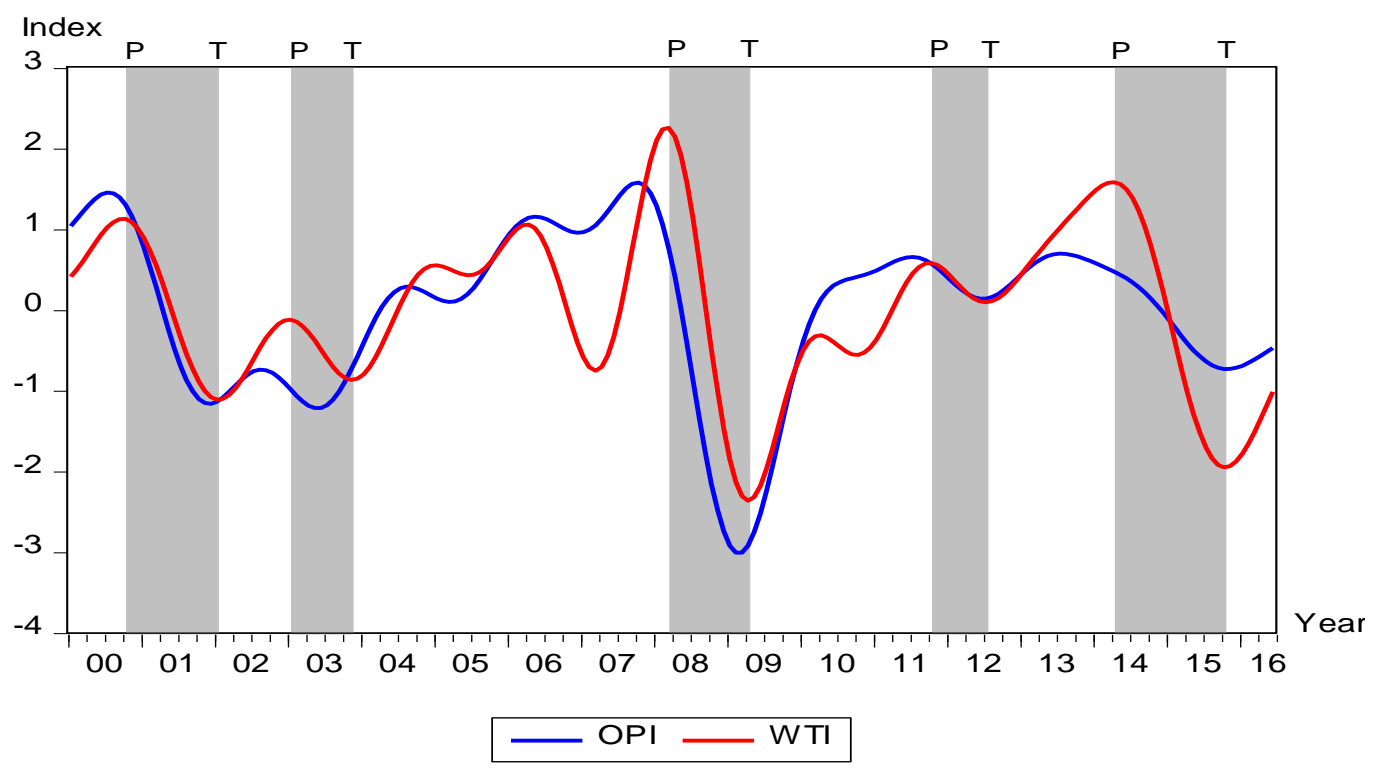

Figure 1. Cyclical Movements of OPI versus WTI, 2000M01-2016M06

Table 1. Turning Points Analysis Results of OPI and WTI

\begin{tabular}{ccccl}
\hline Cycle Condition & WTI & OPI & $\begin{array}{c}\text { Amount of Early } \\
\text { Signals }\end{array}$ & \multicolumn{1}{c}{ Significant Events } \\
\hline Peak & $2000 \mathrm{M} 10$ & $2000 \mathrm{M} 07$ & 3 & 2000s Commodities Boom; September 11 \\
Trough & $2002 \mathrm{M} 01$ & $2001 \mathrm{M} 12$ & 1 & Attack \\
\hline Peak & $2003 \mathrm{M} 01$ & $2002 \mathrm{M} 08$ & 5 & Iraq War \\
Trough & $2003 \mathrm{M} 11$ & $2003 \mathrm{M} 05$ & 6 & Subprime Mortgage Crisis \\
\hline Peak & $2008 \mathrm{M} 03$ & $2007 \mathrm{M} 10$ & 5 & Libyan Civil War \\
Trough & $2009 \mathrm{M} 04$ & $2009 \mathrm{M} 02$ & 2 & Concurrence of Production Oversupply \\
Peak & $2011 \mathrm{M} 10$ & $2011 \mathrm{M} 07$ & 3 & \\
Trough & $2012 \mathrm{M} 07$ & $2012 \mathrm{M} 06$ & 1 & and Stagnant Demand \\
\hline Peak & $2014 \mathrm{M} 04$ & $2013 \mathrm{M} 07$ & 9 & \\
Trough & $2015 \mathrm{M} 10$ & $2015 \mathrm{M} 10$ & - & \\
Average & & & $\mathbf{3 . 5}$ months & \\
\hline & & & &
\end{tabular}

Between late 2000 to early 2002, the occurrence of two focal events actually caused the global COPs to plummet, namely the dot-com bubble (also known as technology-stock bubble) as well as the Sept. 11, 2001 attack. In the case of the former event, the COPs started gaining momentum due to the increase of the U.S. and world 
economies, and the latter refers to the unprecedented terrorist attack on the U.S., which brought up many uncertainties, and the negative prospects for the U.S. economy were vast. The subsequent turning points included the Iraq war in 2003 that raised concerns about the stability of the Middle East's crude oil production. Next, important events in oil price history affected the subprime-mortgage crisis that happened from 2008 to 2009 , whereby this global financial crisis led a bubble-bursting sell-off as well as a collapse in crude oil demand. Furthermore, during the period of 2011 to 2012, another conflict between countries took place, i.e. the Libyan civil war. Riots and protests from the Arab Spring washed over the Middle East, and the war disrupted the region's crude oil output. The fifth event worth mentioning is the ongoing oil price shocks after the production oversupply and weak demand for crude oil. Strong production in the U.S. and Russia caused the COPs to crash from July to December 2014. OPEC made a firm decision in November 2014 to maintain its productions, and this further damaged the market heading into 2015.

\section{Conclusion}

In an effort to better predict the cycle of the global COPs, this study utilized the indicator approach by NBER to construct a leading oil price indicator. This is a novel endeavor as a forecasting tool, despite the enormous forecasting efforts by other researchers in using other econometric techniques other than the indicator method. An average lead of 3.5 months by the constructed OPI in forecasting the cycle of global COPs is believed to help oil-exporting nations control their production as well as signal to other commodities in the market that are led and guided by the global crude oil performance.

This study has yet to overcome certain limitations. The geopolitical event is one of the factors that should be considered in analyzing the COPs. However, it is difficult to predict and capture data regarding this aspect, because no one can provide an accurate proxy for it simply through values or numbers with appropriate rationale. To a certain extent, the weather in oil-producing nations has always been a concern that could influence the crude oil production, just as the events in Oklahoma City surrounding Hurricane Katrina in 2005, which hugely decreased production, and consequently, oil price spiked. Future study may seek to widen the scope of selecting the causes of global crude oil in an attempt to improve the current constructed OPI.

\section{Acknowledgments}

Financial support from Universiti Malaysia Sarawak (UNIMAS) and Fundamental Research Grant Scheme [FRGS/SS08(04)/1295/2015(12)] are gratefully acknowledged.

\section{References}

Abramson, B., \& Finizza, A. (1991). Using belief networks to forecast oil prices. International Journal of Forecasting, 7(3), 299-315. https://doi.org/10.1016/0169-2070(91)90004-F

Abu Mansor, S., Puah, C. H., Liew, V. K. S., \& Wong, S. S. L. (2015). An early warning indicator of economic vulnerability constructing for Malaysian economy. Economic Annals-XXI, 3(1), 37-41.

Agnolucci, P. (2009). Volatility in crude oil futures: A comparison of the predictive ability of GARCH and implied volatility models. Energy Economics, 31(2), 316-321. https://doi.org/10.1016/j.eneco.2008.11.001

Aloui, C., \& Jammazi, R. (2009). The effects of crude oil shocks on stock market shifts behavior: A regime switching approach. Energy Economics, 31(5), 789-799. https://doi.org/10.1016/j.eneco.2009.03.009

Azadeh, A., Moghaddam, M., Khakzad, M., \& Ebrahimipour. (2012). A flexible neural network-fuzzy mathematical programming algorithm for improvement of oil price estimation and forecasting. Computers and Industrial Engineering, 62(2), 421-430. https://doi.org/10.1016/j.cie.2011.06.019

Bry, G., \& Boschan, C. (1971). Cyclical analysis of time series: Selected procedures and computer programs. New York: National Bureau of Economic Research.

Cheong, C. W. (2009). Modeling and forecasting crude oil markets using ARCH-type models. Energy Policy, 37(6), 2346-2355. https://doi.org/10.1016/j.enpol.2009.02.026

Christiano, L. J., \& Fitzgerald, T. J. (2003). The band pass filter. International Economic Review, 44(2), 435-465. https://doi.org/10.1111/1468-2354.t01-1-00076

Cong, R. G., Wei, Y. M., Jiao, J. L., \& Fan, Y. (2008). Relationships between oil price shocks and stock market: An empirical analysis from China. Energy Policy, 36(9), 3544-3553. https://doi.org/10.1016/j.enpol.2008.06.006

Haas, M., Mittnik, S., \& Paollela M.S. (2004). A new approach to Markov-switching GARCH models. Journal of Financial Econometrics, 2(4), 493-530. https://doi.org/10.1093/jjfinec/nbh020 
Jo, S. J. (2012). The effects of oil price uncertainty on the macroeconomy. Bank of Canada Working Paper No. 2012-40.

Moore, G. H., \& Zarnowitz, V. (1986). The development and role of the National Bureau of Economic Research's business cycle chronologies. In R.J. Gordon (Ed.), The American Business Cycle: Continuity and Change (pp.735-779). Chicago: University of Chicago Press.

Pan, H., Haidar, I., \& Kulkarni, S. (2009). Daily prediction of short-term trends of crude oil prices using neural networks exploiting multimarket dynamics. Frontiers of Computer Science in China, 3(2), 177-191. https://doi.org/10.1007/s11704-009-0025-3

Park, J., \& Ratti, R. A. (2008). Oil price shocks and stock markets in the US and 13 European countries. Energy Economics, 30(5), 2587-2608. https://doi.org/10.1016/j.eneco.2008.04.003

Puah, C. H., Kuek, T. H., Arip, M. A., \& Wong, S. S. L. (2016b). Forecasting property market dynamics: Insights from the property cycle indicator. Information, 19(6B), 2225-2232.

Puah, C. H., Tan, W. T., Abu Mansor, S., \& Wong, S. S. L. (2016a). Tackling macroeconomic precariousness: The role of the composite leading indicator. Information, 19(6B), 2217-2224.

Soytas, U., Sari, R., Hammoudeh, S., \& Hacihasanoglu, E. (2009). World oil prices, precious metal prices and macroeconomy in Turkey. Energy Policy, 37(12), 5557-5566. https://doi.org/10.1016/j.enpol.2009.08.020

The Conference Board. (2000). Business Cycle Indicator Handbook. New York: The Conference Board.

Wong, K. K. S., \& Shamsudin, M. N. (2017). Impact of crude oil price, exchange rates and real GDP on Malaysia's food price fluctuations: Symmetric or asymmetric? International Journal of Economics and Management, 11(1), 259-275.

Wong, S. S. L., Puah, C. H., Abu Mansor, S., \& Liew, V. K. S. (2016). Measuring business cycle fluctuations: An alternative precursor to economic crises. Economic Computation and Economic Cybernetics Studies and Research, 50(4), 235-248.

\section{Technical Notes}

1. The symmetric percentage change calculation as shown in Equation 1 needs to be done at foremost because the component series must firstly be ensured its smoothness, or in other words it shall not be too erratic in its month-to-month movement. Thereby standard deviation is calculated for component series.

2. Next, the inverse of standard deviation of the symmetric changes in each component series is calculated and the values are all summed up together. Each of the inverse value is then divided by the sum value in order to get the standardization factor $\left(f_{p}\right)$ of each component series and it is then normalized to sum to one.

3. Standardization factors determine how monthly changes in each component contribute to the monthly change in the index of OPI. These factors are designed to give each component a similar opportunity to contribute to the change in the index in any given month. Adjustments equalize the volatility of each component in the index.

\section{Copyrights}

Copyright for this article is retained by the author(s), with first publication rights granted to the journal.

This is an open-access article distributed under the terms and conditions of the Creative Commons Attribution license (http://creativecommons.org/licenses/by/4.0/). 